\title{
Study of Impementation of Total Quality Management for Defect Reduction in Manufacturing Industry
}

\author{
Suman Rani1 ${ }^{1}$ Raj Kumar Duhan ${ }^{1}$ and Sandeep Deshwal ${ }^{2}$ \\ Department of Mechanical Engineering, University Institute of Engineering \& Technology, Rohtak, \\ Haryana, India. \\ Department of Mechanical Engineering, PDM College of Engineering (Bahadurgarh), Haryana, India.
}

\begin{abstract}
The purpose of this paper is to discuss the effect of implementation of total quality management $(T Q M)$ in manufacturing industry (Mohindra Fasteners Ltd.). Very few service companies have been able to reap full benefits of TQM. One major reason for its inadequate success is that of trying to implement in service companies techniques that have been successful in manufacturing. In manufacturing, emphasis of TQM is on "zero defects". Control charts and sampling are the major tools of quality control. However, in services, emphasis is on "zero defections". Focus is on customer satisfaction and team approach. TQM can boost profits and improve customer satisfaction by reducing deffects.
\end{abstract}

\section{Introduction}

Total Quality management is an important task in today's business activities that aims at customer satisfaction. Achieving a high quality product either enables a firm to differentiate its products or move close to product differentiation. The reality is that, firms that adopt total quality management improve firms organisational performance. The important consideration is that, modern environment attaches great importance to the role of market competition in the determination of company's profitability and generally creates unrest to the management personnel. This is due to the fact that understanding the marketing environment such as number and size of competitors, government policies, and economic situation including level of demand is essential. Many manufacturing companies encounter different operational problems, parts of which include insufficient materials, management problems, inadequate and poor infrastructures. This paper therefore examines the extent to which manufacturing industry achieve total quality management for reducing the defect up to zero level.

\section{Literature Rewiew}

Total quality Control Management was developed in the mid 1940s by Dr. W. Edward Deming who at the time was an advisor in sampling at the Bureau of Census and later became a professor of statistics at the New York University Graduate School of Business Administration. He had little success convincing American business to adopt TQM but his management methods did gain success in Japan. In the 1970s and 1980s, many American companies, including Ford, IBM, and Xerox, began adopting Dr. Deming's principles of TQM. This gradually led to their remaining some of the markets previously lost to the Japanese. Although TQM gained its performance in the private sector, in recent years it has been adopted by some public organizations. Tools and techniques of TQM are applicable to a wide range of organizations of all sizes and types such as manufacturing, service, government, military, contraction, education, small business , healthcare and non profit entities.

There are many assumptions about quality, from the simple definitions till the complicated ones. Some definitions are listed below.

Quality is fitness for use (Juran, 1989).

Quality is conformance to requirements (Crosby, 1996).

Quality should be aimed at the needs of the consumer, present and future (Deming, 1986).

Quality is the total composite product and service characteristics of marketing, engineering and maintenance through which the product and service in use will meet the expectations of the customer (Feigenbaum, 1991).

Quality is the totality of features and characteristics of a product or service that bear on its ability to satisfy stated or implied needs (ISO 9000).

The American National Standards Institute (ANSI) and the American Society for Quality Control (ASQC) 1978, define quality as the totality of features and characteristics of a product or service that bears on its ability to satisfy given needs.

The European Foundation for Quality Management (EFQM) defines quality as to meet the needs and expectations of the customers, personnel, financial stakeholders and society (Geraedts, et al., 2001).

Based on the definitions above, it can be concluded that quality is focused on customer. Customer focused quality is driven by customer satisfaction and has become the principle definition of quality from a 
managerial perspective. Quality is meeting and exceeding customer needs and expectations. Quality is defined by product specifications and achieved by manufacturing. The most applicable definitions are fitness for use (the design perspective) and conformance to specifications (the manufacturing perspective) where both are necessary for customer satisfaction (Evans and Lindsay, 1993).

\section{Quality Evolution}

In accordance with the development of technology and the ideas of authors, the differences of opinion on definition of quality has undergone an evolution. In the early 1900s, Frederick W. Taylor led a new philosophy of production. By decomposing a job individual work tasks, inspection tasks, which led to the creation of separate quality department in production organizations. However, Walter A. Shewhart considered the use of statistics as a vital in the effort to improve quality (Evans and Lindsay, 1993). He developed control charts to track performance over time thereby providing workers with the ability to monitor their work and predict when they were about to exceed limit and possibly produce scrap.

Different from the conventional definition of quality, Crosby's approach to quality were basically built around four fundamental beliefs:

Crosby defines quality as "conformance to requirements, not elegance". The quality system for suppliers attempting to meet customers' requirements is to do it right the first time-prevention, not inspection. The performance standard is ZERO DEFECTS. The measurement of quality is the cost of quality. competition that changed customer requirements and forced the implementation of new technologies and philosophies of production and management.

\section{T Q M}

Total quality management (TQM) is an enhancement to the traditional way of doing business. It is a proven technique to guarantee survival in world-class competition (Besterfield, 2001). Only by changing the actions of management will the culture and actions of an entire organization be transformed. Besterfield (2001) defined Total means made up of the whole; Quality means degree of excellence a product or service provides; Management means act, art or manner of handling, controlling, directing, etc. Therefore, TQM is the art of managing the whole to achieve excellence. TQM is defined as both a philosophy and a set of guiding principles that represent the foundation of a continuously improving organization (Besterfield, 2001). Further more Besterfield stated that TQM requires five basic concepts:

A committed and involved management to provide long-term top-to-bottom organizational support.

An unwavering focus on the customer, both internally and externally.

Effective involvement and utilization of the entire work force.

Continuous improvement of the business and production process.

Treating suppliers as partners.

In this method defect is reduce by using several steps:

Step 1: Conference meeting of relevant staff

Step 2: Present the problem (defect).

Step 3: Brainstorming

Step 3: Data collection relevant to improvement of task

Step 4: Analysis of data and collect feasible ideas of improvement

Step 5: Team building

Step 6: Target distributed to complete the task

Step 7:Use various quality tools to solve the problem.

Step 8: Implementing the correct method for reducing the defect up to zero.

e.g 


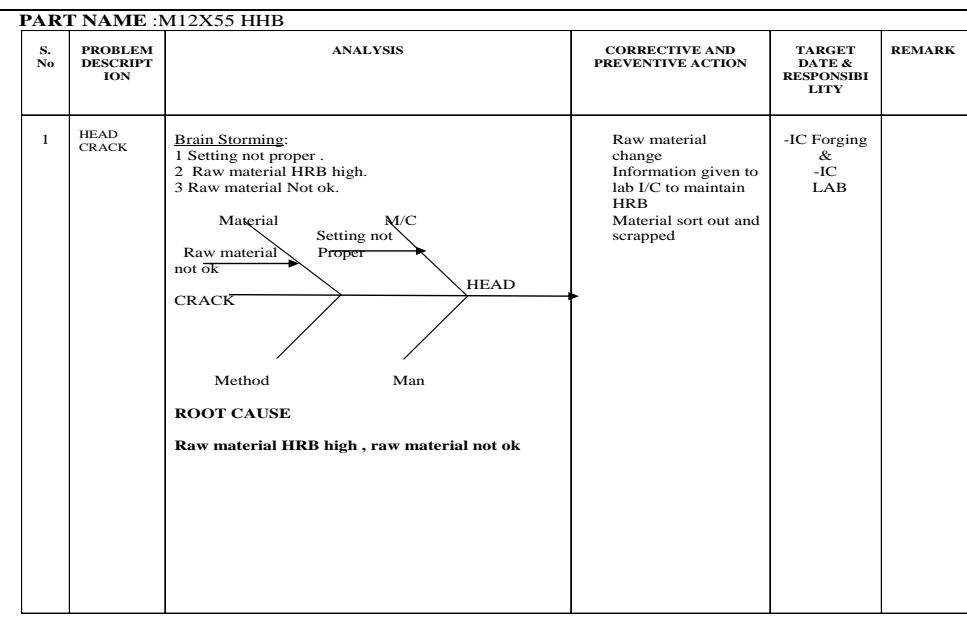

\section{Objective Of Study}

1. To study the philosophy and concept of TQM.

2. To analyze the implementation of TQM in manufacturing industry.

3. To reduce the defects in various items by implementing TQM.

3. To analyze the constraints and benefits of TQM in manufacturing industry.

\section{Findings Of Study}

Total Quality Management is a system implemented to reduce defects in finished products with the goal of achieving zero defect products these systems requires timely data on defective products, rework costs, and the cost of honoring warranty contracts. This information is used to help to redesign the product in a way that makes it less prove to defect. It may be used to reengineer the production process to reduce set up time and decrease the potential for error. TQM systems provide information on non-financial measures such as customer satisfaction, number of since calls and time to generate reports. Attention to these measures which employees can control leads to increased profitability. Just in time inventory systems demand for an increased emphasis on product quality. If products are produced only as they are needed. It is very costly for the company to have to stop production became of defects or machine breakdown. TQM and just in time production often aid in effective application of the learn business model. The main purpose of lean business model is to eliminate waste and strive for continuous improvement which requires that every manager and employee continuously look to improve operations. TQM calls for all managers and employees at all stages of operations to strive towards higher standards and a reduced number of defects. In today's competitive and international market place, quality is synonymous with not just product quality but also cost, delivery and service. In a global market where product life cycle has become short where customer expectations have increased, the traditional product testing/certification approaches are not adequate. To compete in international markets, companies in developing countries need a sound quality management system. With liberalization and international competitiveness, there is a need to improve the quality of goods manufactured by the industries.

Standardization is one of the important tools for achieving quality up gradation and building a strong quality culture within the organization market place, quality is synonymous with not just product quality but also cost, delivery and service. In a global market where product life cycle has become short where customer expectations have increased, the traditional product testing/certification approaches are not adequate. To compete in international markets, companies in developing countries need a sound quality management system. With liberalization and international competitiveness, there is a need to improve the quality of goods manufactured by the industries.

Standardization is one of the important tools for achieving quality up gradation and building a strong quality culture within the organization.

\section{Limitation \& Conclusions}

There are several limitations in TQM implementation some of them are:

1. Lack of management commitment.

2. Inability to change organizational culture.

3. Improper planning.

4. Lack of continous training and education.

5. Incompatible organization structure.

6. Paying inadequate attention to internal and external customers. 
TQM attempts to have maximum customer satisfaction through providing quality products and services but uncongenial business environment, high cost of production, increasing prices of products unfair competition in market are the major constraints in using TQM. Once the business is profitable, they can develop quality products and services. Absence of breakeven point decline in demand for products, lack of trained manpower are other limiting factors for such use. We should try to have market research to satisfy our customers as well as managerial efficiency and effectiveness sidely side.

\section{References :}

1. Barry, T.J., Management Excellence through quality (Milwaukee; ASQC Quality Press, 1991).

2. Bendell, T., and R.M.G. Milar, Taguchi Methodology with Total Quality (Bedford: IFS, 1990).

3. Berryt, T.H. Managing the Total Quality Transformation (Milwaukee: ASQC Quality Press, 1991).

4. Besterfield, Dale H., Quality Control (Englewood Cliffs, N.J.; Prentice - Hall Inc., 1990).

5. Dean, J. W. and Evans. J. R. (1994), Total Quality Management, Organization and Strategy, NY

6. Garvin, David A. (1988), Managing Quality - The Strategic and Competitive Edge; The Free Press; NY

7. Goetsch, David L. and Davis, Stanley B. (1997), "Introduction to Total Quality", 2nd ed., New Jersy: Prentice Hall 